\title{
Factors associated with tuberculosis diagnosis and treatment delays in Middle East and North Africa: a systematic review
}

Dalya Eltayeb, ${ }^{1}$ Elize Pietersen, ${ }^{2}$ Mark Engel ${ }^{2}$ and Leila Abdullahi ${ }^{3}$

${ }^{1}$ Department of Public Health and Family Medicine; ${ }^{2}$ Department of Medicine, Faculty of Health Sciences; ${ }^{3}$ Vaccines for Africa Initiative, University of Cape Town, Anzio Road Observatory, Cape Town, South Africa (Correspondence to: Dalya Eltayeb: dalyaeltayeb@gmail.com).

\begin{abstract}
Background: Political instability, economic sanctions and substandard quality of health care negatively affect tuberculosis (TB) control in the Middle East and North Africa (MENA) region.
\end{abstract}

Aims: We aimed to elucidate factors contributing to delays in TB diagnosis and treatment in MENA countries.

Methods: Two reviewers independently appraised eligible articles identified through comprehensive searching and extracted data which were subjected to meta-analysis.

Results: Delays in TB diagnosis were associated with older age and low income [(OR $=1.49 ; 95 \%$ CI: 1.31-1.70) and $(\mathrm{OR}=$ 1.26; 95\% CI: 1.09-1.45)] respectively ( $\mathrm{n}=17$ studies). Being female was associated with patient delay and health system delay $[(\mathrm{OR}=1.24 ; 95 \% \mathrm{CI}: 1.02-1.50)$ and $(\mathrm{OR}=1.68 ; 95 \% \mathrm{CI}: 1.18-2.38)]$ respectively. Knowledge and perception of TB, having employment and low levels of crowding were each protective against patient delay. The GRADE system rated the evidence as of low quality.

Conclusion: This review provides evidence for facilitators and barriers to TB diagnosis and health system delays. For successful TB control in the MENA region, TB awareness and interventions targeting the elderly and those from lower-income settings, particularly directed at gender differences, are essential.

Keywords: Tuberculosis case finding, delayed diagnosis, tuberculosis control, Middle East and North Africa, health care-seeking behaviour, delivery of health care

Citation: Eltayeb D; Pietersen E; Engel M; Abdullahi L. Factors associated with tuberculosis diagnosis and treatment delays in Middle East and North Africa: a systematic review. East Mediterr Health J. 2020;26(4):477-487. https://doi.org/10.26719/2020.26.4.477

Received: 12/02/18; accepted: 30/08/18

Copyright @ World Health Organization (WHO) 2020. Open Access. Some rights reserved. This work is available under the CC BY-NC-SA 3.0 IGO license (https://creativecommons.org/licenses/by-nc-sa/3.o/igo).

\section{Introduction}

Tuberculosis (TB) remains a major global health problem (1). In 2015, an estimated 4.3 million cases were neither detected nor treated in national TB programmes globally (1).

A diagnostic delay of two months will result in transmission of TB to an average of 8 contacts (2) and within a year, this number will increase eight to 15 persons; the increase would be even higher in settings of overcrowding and higher social capital (3). Furthermore, delays between admission and initiation of treatment will result in the exposure to TB of an average of 23.9 health care workers (4). Therefore, to curb TB transmission and reduce poor disease outcomes and adverse social and economic consequences, timely diagnosis and prompt initiation of anti-TB treatment is vital (5).

Reasons for delayed TB diagnosis can be attributed to both patients and the health care system (6). Patients may delay in seeking help while the health care system may delay in suspecting $\mathrm{TB}$ and initiating relevant investigations. Delays, and ultimately TB control, are affected by patient factors such as sociodemographic characteristics, stigmatization effects of $\mathrm{TB}$, fear of high individual expenses, symptoms on presentation and health care factors such as absence of a refined TB suspicion index, infrastructure and organization of the health system (7).

The World Bank's description of the Middle East and North Africa (MENA) region covers the 21 members of the Arab League, plus the Islamic Republic of Iran, Israel and Turkey (8). The MENA region is challenged with delayed detection of $\mathrm{TB}$, which negatively affects treatment and control in the region (9). Factors in the region that have destabilized health care delivery are political instability and economic sanctions. Health care resources are thus stretched beyond control, and the quality of health care service delivery deteriorated to a level that can be described as "below standard" (9).

There is a scarcity of systematic reviews addressing TB diagnostic and treatment delays (10). Furthermore, these reviews included older studies, are applicable to high HIV prevalence settings, and specifically did not include diagnostic and treatment delays in MENA countries.

We conducted a systematic review to address this paucity of data. We wished to evaluate the evidence regarding factors associated with $\mathrm{TB}$ diagnostic and treatment delays in the MENA region. Successful identification of such factors may actually lead to interventions which may ultimately increase effective TB control. 


\section{Methods}

\section{Protocol}

The review protocol has been published in the PROSPERO International Prospective Register of systematic reviews, (http://www.crd.york.ac.uk/PROSPERO) registration number CRD42015023337.

\section{Search methods for identification of studies}

This systematic review adheres to Preferred Reporting Items for Systematic reviews and Meta-Analyses (PRISMA) guidelines 2009 (11). We searched MEDLINE using combinations of the following keywords: TB, tuberculosis, mycobacterium, patient delay, health seeking delay, care-seeking delay, health system delay, health facility delay, health provider delay, diagnosis delay, total delay and treatment delay. Key terms (factors or enablers and barriers) that did not provide new articles were excluded from the final search strategy. Search strategies incorporated both medical subject headings $(\mathrm{MeSH})$ and freetext terms using controlled vocabularies applicable to databases. Published and unpublished articles, irrespective of language used, were interrogated up to June 2015.

Electronic searches were carried out on the following published databases: Cochrane Central Register of Controlled Trials (CENTRAL), Web of Science, PubMed, CINAHL, Psychlnfo and Scopus. Grey literatures were searched using Index Medicus for the Eastern Mediterranean Region (IMEMR), (Africa-wide) allied health and Google scholar. In addition, we searched conference proceedings and reference lists of relevant articles.

Observational studies (case-control, cross-sectional and population-based) were considered for review. Studies which reported patient and health system delays in patients diagnosed with, or suspected of, pulmonary TB (PTB) were included. Andersen's behavioural model of health care utilization was used to classify factors regarded as primary outcomes for the study (12). These factors were defined as predisposing factors (factors influencing the initial performance of behaviour); enabling factors (factors making it possible for individuals to enact their behaviour) and need factors (factors following behaviour enactment and influence continued behaviour). Secondary outcomes were: magnitude of patient delay (defined as time interval from onset of TB symptoms to first visit of any health provider), health system delay (defined as time interval from the first health provider visit to initiation of treatment) and total delay, which includes both patient and health system delays (defined as time interval from onset of TB symptoms to initiation of treatment).

\section{Data collection and analysis}

\section{Selection of studies and data extraction}

Two reviewers (DE and EP) independently screened titles and abstracts of all identified articles to select potential eligible studies; reviewed full texts of potentially eligible studies; nominated the final set of articles for inclusion into the review; extracted data using a standardized data extraction form and reviewed risk of bias. A third reviewer ( $M E$ or LA) facilitated disagreements regarding study selection and data extraction.

\section{Assessment of risk of bias}

We noticed a 2-study design, a descriptive phase and an analysis phase, in 12/20 studies. In these studies the descriptive phase, a cross-sectional design, was used to determine the extent of delay while during the analysis phase, a nested case-control design, patient delay was compared to the median time of delay. The quality of these studies was assessed based on results from the analysis phase. Two authors used the Newcastle-Ottawa Quality Assessment Scale for case-control studies (13) to assess the risk of bias in these 12 studies.

Cross-sectional and descriptive surveys were assessed according to an assessment tool by Hoy et al. (14) as adapted by Werfalli et al. (15). This adapted assessment tool allows for allocation of a composite score to assist with relative comparison between studies.

\section{Data analysis and synthesis}

The results of each study were expressed as an odds ratio (OR) with the corresponding $95 \%$ confidence interval (CI) for dichotomous data. Studies that compared similar types of outcomes were grouped to get feasible results on an overall estimate of effect. Random effects meta-analysis was used due to heterogeneity in study results. Prevalence of TB delay from different studies was pooled in a meta-analysis using Review Manager, 5.3.

\section{Assessment of heterogeneity and subgroup analysis}

Statistical heterogeneity between the study results were examined using the $\chi^{2}$ test for homogeneity (with significance defined at the alpha-level of $10 \%$ ) and quantified using the I-squared statistic. The $\chi^{2}$ test for subgroup differences was used to test for subgroup interactions.

\section{Grading the quality of evidence}

We used GRADEpro software to appraise limitations to validity in terms of the quality of evidence on the $12 / 20$ observational studies pooled in the meta-analysis.

\section{Results}

\section{Study flow and description of studies}

Full-text evaluations were performed on 32 articles, of which 12 were deemed unsuitable for inclusion in the review (Figure 1) (references available from corresponding author upon request). Reasons for exclusion were: in 2 studies participants did not meet the inclusion criteria; in 2 other studies participants were not from the MENA countries; and in the last 8 studies the outcomes measures did not address TB delay.

The 20 studies included in this systematic review were published between 2001 and 2015; 18 had a cross-sectional study design while 2 were nested case-control studies. Participants included in the studies ranged from TB 
Figure 1 Flow diagram of studies selected for inclusion in the systematic review

324 studies identified and screen $\quad \mathrm{d}$

- 303 from electronic databases and trail registrit es

- 20 from hand searchin $\quad \mathrm{g}$

- 1 from contact with authe or

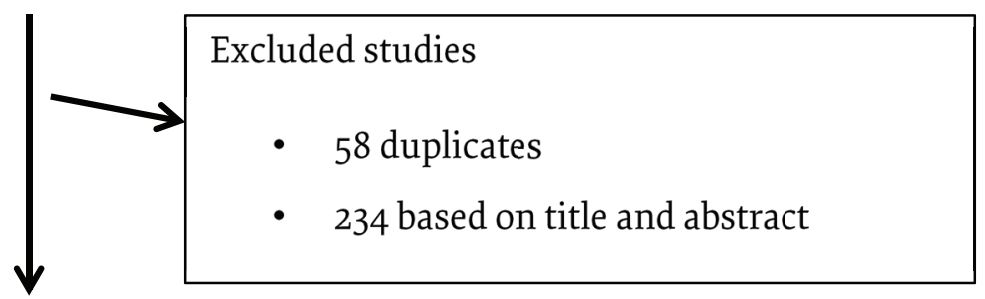

32 studies: conducted full text reviev $\quad \mathrm{v}$

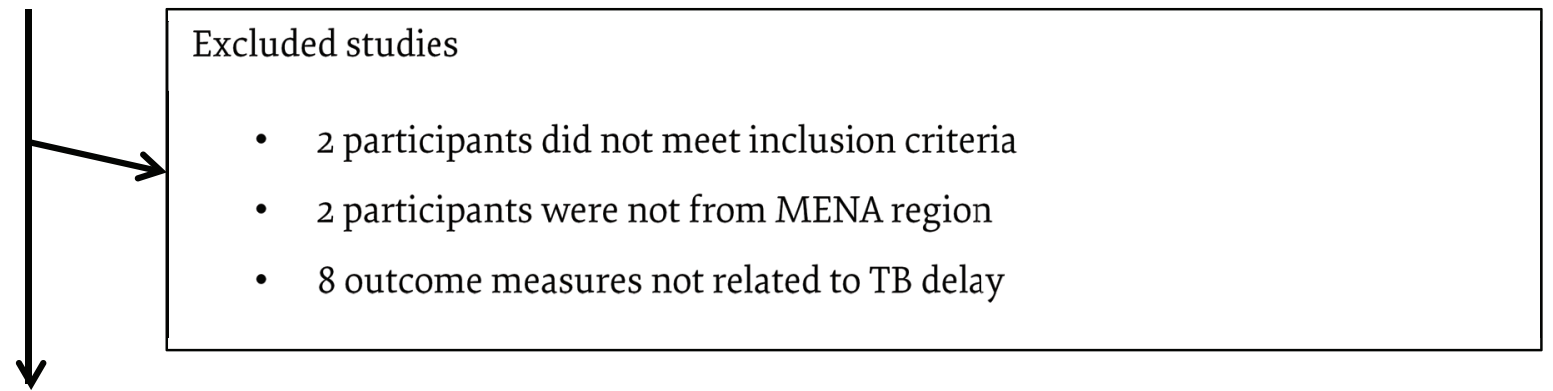

20 studies from MENA countries included in systematic review:

- 6 Iran

$[18,26,27,28,32,33]$

- 5 Turkey

$[17,19,29,30,34]$

- 2 Yemen

$[20,35]$

- 2 Syria

$[21,31]$

- 2 Sudan

$[22,23]$

- 1 Jordan

[16]

- 1 Morocco

[24]

- 1 multi-country

[25] (Iraq, Islamic Republic of Iran, Egypt, Somalia)

suspects (1 study) (16), smear negative and smear positive PTB patients (2 studies) $(17,18)$ ) and only new smearpositive patients (17 studies) (19-35). Almost all studies used a consecutive method of sampling and sample sizes ranged from 50 to 5702 . Male sex was dominant in all of the studies and the majority were conducted in both urban and rural settings (detailed characteristic of studies included in the systematic review available upon request).
Sixteen studies assessed both sources of delay; 4 assessed only patient delay while 2 assessed total delay without any demarcation between patient and health system delay. Seventeen studies measured the duration of patient delay, of which only 10 analysed the factors attributed to this period $(16,22,27,28,30-35)$. Out of 15 studies that measured the duration of health system delay, 6 analysed at least 1 factor associated with this period $(22,23,26,32,34,35)$. 


\section{Assessment of risk of bias}

We found 11 studies had a low risk of bias (16,19-25a-25d), 7 had a moderate risk of bias (17,26-31) and 5 had a high risk of bias (18,32-35) (Tables 1,2). We considered the WHO report as a single study with coverage of 4 countries that met our inclusion criteria (25).

\section{Patient delay}

Patient delay was measured in 17/20 studies. Measures of patient delay depended on patient recall of first symptoms for PTB. The majority of studies measured delay as a dichotomous variable based on a cut-off point, usually the median. The shortest (12.5 days) and longest (73 days) mean duration of patient delay was reported in the Islamic Republic of Iran $(26,33)$. However, the quality of these studies should be considered before drawing any conclusion from this observation.

\section{Factors associated with patient delay}

At least one factor attributing to patient delay was analysed in 10 studies $(16,18-25,35)$. Studies mostly assessed predisposing factors such as patient sociodemographic characteristics, TB knowledge and perception about TB. Enabling factors were less often assessed, while none of the studies assessed at least one needs factor.

Predisposing factors that were significantly associated with patient delay were older age $(\mathrm{OR}=1.24$; 95\% CI: 1.02 to 1.50 ), female sex (OR $=1.42 ; 95 \%$ CI: 1.19 to 1.69), unemployment ( $\mathrm{OR}=0.83 ; 95 \% \mathrm{CI}$ : 0.72 to 0.95 ), low patient income ( $\mathrm{OR}=1.95 ; 95 \% \mathrm{CI}: 1.07$ to 3.55$)$ and low crowding index (OR $=0.75 ; 95 \%$ CI: 0.57 to 0.99$)$ (Figure 2).

Factors found to be significantly associated with patient delay were: inadequate ТВ knowledge $(20,25 a)$, although in 4 studies the summary OR was not significant for literacy $(16,20,21,35)$; residing in rural areas (16); presence of chronic health problem $(21,22)$; contact with a TB case (21) [yet protective against delay in another study (19)]; self-medication (25a) [although not significantly associated in another study (23)]; and high cost of medical services (20).

Factors found to be protective against patient delay were high TB perception (16,35); however, this predisposed to delay in 1 study (22); TB-related stigma was found to be protective from patient delay in 1 study (16) and predisposed to patient delay in another (25a). Marital status, smoking, a HIV positive status and travelling time were not associated with patient delay in any of the studies that interrogated these factors.

Health care provider (OR $=0.77 ; 95 \% \mathrm{CI}$ : 0.70 to 0.85 ) (Figure 2) was the only enabling factor that had sufficient information to calculate summary OR. The type of provider at first consultation, i.e. consulting a non-health care provider, was associated with extended patient delay $(19,20,21,23,25 a)$. The high cost of medical services was significantly associated with patient delay in one study (20).

\section{Health system delay}

Duration of health system delay was measured in 15/20 studies. All 15 studies used the health facility's record of first consultation as entry point to health care and 13/15 used start of treatment as the endpoint of time spent in the health system. Two studies used TB diagnosis as the endpoint. The majority of the studies measured delay versus non-delay as a dichotomous variable based on a cut-off point, usually the median. In patients who had health system delay, the shortest mean duration of health system delay ( 5 days) was reported in Iraq (25a) whereas the longest mean duration (129.25 days) was reported in the Islamic Republic of Iran (28).

\section{Factors associated with health system delay}

At least one factor associated with health system delay was analysed in 6/15 studies $(19,23-25,29,34)$. Enabling factors such as type of facility, type of providers at first visit, number of visits, number of providers consulted before reaching a TB diagnosis and expenses plus travel time were assessed. These factors were related to the aspect of health system delay in which patient return for diagnosis and treatment were required.

Predisposing factors that assessed health system delay were female sex, older age and patient income. Being female was significantly associated with health system delay (OR $=2.12$; 95\% CI: 1.24 to 3.60 ) (Figure 3) in 3 studies that contributed to the summary OR $(19,23,24)$. Older age and patient income were not associated with health system delay in any of the studies that interrogated this factor. The enabling factors that were associated with health system delay were: high cost of medical services (25c); visiting a non-health care provider, i.e. a traditional healer and community or village healer at first visit (25c); more than 3 visits to a health care provider (24); and repeated visits to the same provider (23). Studies that reported lack of examination of sputum on the first visit $(25 b)$, obtaining a negative smear result for acidfast bacilli (25b) and underutilization of chest X-ray and smear microscopy (Turkey and Sudan) (19,23), and a low suspicion index in 3 studies from Turkey $(17,19,34)$ were not combinable to calculate the OR.

Visiting a public, compared with a private facility, at first consultation was the only enabling factor that we had sufficient information for to calculate summary OR. In 3 studies $(21,24,25 b)$, visiting a private facility was significantly associated with health system delay $(\mathrm{OR}=$ $1.41 ; 95 \%$ CI: 1.06 to 1.88 ) (Figure 3).

\section{Heterogeneity}

\section{Patient delay factors}

Heterogeneity was significant in terms of sex $\left(P<0.1 ; I^{2}=\right.$ $45 \%)$, patient's income $\left(P<0.00001 ; I^{2}=92 \%\right)$, and crowding $\left(P=0.15 ; I^{2}=47 \%\right)$. Upon further investigation, we found one study as the source of heterogeneity in terms of sex (16). Participants in this study were TB suspects rather than the confirmed TB cases in the other studies. 


\begin{tabular}{|c|c|c|c|c|c|c|c|c|c|c|}
\hline \multirow[t]{2}{*}{ Study } & \multicolumn{3}{|c|}{$\mathbf{A}$} & \multicolumn{3}{|c|}{ B } & \multicolumn{3}{|c|}{ C } & \multirow{2}{*}{$\begin{array}{l}\text { Quality } \\
\text { score }\end{array}$} \\
\hline & A1 & A2 & A3 & $\mathrm{A}_{4}$ & B1 & B2 & $\mathrm{C}_{1}$ & $\mathrm{C}_{2}$ & $C_{3}$ & \\
\hline $\begin{array}{l}\text { Al-Absi } 2006 \\
\text { Yemen (20) }\end{array}$ & 1 & 1 & 0 & 0 & 1 & 1 & 0 & 1 & 1 & 6 \\
\hline $\begin{array}{l}\text { Alavi et al. } 2015 \\
\text { Iran (18) }\end{array}$ & 1 & 1 & 0 & 0 & 0 & 0 & 0 & 1 & 1 & 4 \\
\hline $\begin{array}{l}\text { Akrim et al .2014 } \\
\text { Morocco (24) }\end{array}$ & 1 & 1 & 1 & 1 & 1 & 1 & 0 & 1 & 1 & 8 \\
\hline $\begin{array}{l}\text { Date \& Okita } 2005 \\
\text { Yemen (35) }\end{array}$ & 1 & 1 & 0 & 0 & 0 & 0 & 0 & 1 & 1 & 4 \\
\hline $\begin{array}{l}\text { Maamari } 2008 \\
\text { Syria (21) }\end{array}$ & 1 & 1 & 1 & 1 & 1 & 1 & 0 & 1 & 1 & 8 \\
\hline $\begin{array}{l}\text { Güneylioglu et al. } 2004 \\
\text { Turkey (19) }\end{array}$ & 1 & 1 & 1 & 1 & 0 & 0 & 0 & 1 & 1 & 6 \\
\hline $\begin{array}{l}\text { Mohamed et al. } 2013 \\
\text { Sudan (22) }\end{array}$ & 1 & 1 & 1 & 1 & 0 & 0 & 0 & 1 & 1 & 6 \\
\hline $\begin{array}{l}\text { Rahim et al.2004 } \\
\text { Sudan (23) }\end{array}$ & 1 & 1 & 1 & 1 & 1 & 1 & 1 & 1 & 1 & 9 \\
\hline $\begin{array}{l}\text { Rumman et al. } 2008 \\
\text { Jordan (18) }\end{array}$ & 1 & 1 & 1 & 1 & 1 & 1 & 0 & 1 & 1 & 8 \\
\hline $\begin{array}{l}\text { WHO } 2008 \\
\text { Iraq (25a) }\end{array}$ & 1 & 1 & 0 & 0 & 1 & 1 & 0 & 1 & 1 & 6 \\
\hline $\begin{array}{l}\text { WHO } 2008 \\
\text { Iran (25b) }\end{array}$ & 1 & 1 & 1 & 1 & 1 & 1 & 0 & 1 & 1 & 8 \\
\hline $\begin{array}{l}\text { WHO } 2008 \\
\text { Egypt (25c) }\end{array}$ & 1 & 1 & 1 & 1 & 1 & 1 & 0 & 1 & 1 & 8 \\
\hline $\begin{array}{l}\text { WHO } 2008 \\
\text { Somalia (25d) }\end{array}$ & 1 & 1 & 1 & 1 & 1 & 1 & 0 & 1 & 1 & 8 \\
\hline
\end{tabular}

$A=$ Selection of the study groups: Al right case definition; A2 right controls definition; $\mathrm{A} 3$ the representativeness of the cases; $\mathrm{A} 4$ the representativeness of controls.

$B=$ Comparability of the groups: B1 control of main confounders; B2 control of any additional factor.

$C=$ Ascertainment of exposure: $C 1$ appropriate method of exposure ascertainment; $C 2$ same method of exposure ascertainment for cases and controls; $C_{3}$ same non-response rate of case and control groups.

1: study met the criteria; 0 : the study did not meet the criteria.

Quality score: $\leq 5$ high risk of bias. $>5$ low risk of bias

\begin{tabular}{|c|c|c|c|c|c|c|c|c|c|c|c|}
\hline Study & A1 & A2 & A3 & A4 & B1 & B2 & B3 & B4 & B5 & B6 & $\begin{array}{l}\text { Quality } \\
\text { score }\end{array}$ \\
\hline Bashour \& Mamaree 2003 (31) & 1 & $\mathrm{U}$ & 1 & 0 & 1 & 1 & U & 1 & 1 & 1 & 7 \\
\hline Ekinci et al. 2014 (17) & 1 & U & U & U & 1 & 1 & U & 1 & 1 & 1 & 6 \\
\hline Masjidi et al. 2007 (26) & 0 & 1 & 0 & U & 1 & 1 & U & 1 & 1 & 1 & 6 \\
\hline Mirsaeidi et al. 2007 (27) & 1 & 0 & 0 & U & 1 & 1 & 0 & 1 & 1 & 1 & 6 \\
\hline Okur et al. 2006 (29) & 0 & 0 & 1 & 1 & 0 & 1 & 0 & 1 & 1 & 1 & 6 \\
\hline Okutan et al. 2005 (30) & 0 & 1 & 1 & 1 & 1 & 1 & 0 & 1 & 0 & 1 & 7 \\
\hline Shahriyar et al. 2012 (33) & 0 & 1 & 0 & 0 & 1 & 1 & 0 & 1 & 0 & 1 & 5 \\
\hline Shamaei et al. 2009 (28) & 1 & 1 & 1 & 0 & 0 & 1 & 0 & 1 & 1 & 1 & 7 \\
\hline Nasehi et al. 2012 (32) & 1 & 1 & 1 & 0 & 0 & 0 & 0 & 0 & 0 & 1 & 4 \\
\hline Yilmaz et al. 2001(34) & U & $\mathrm{U}$ & $\mathrm{U}$ & U & 1 & 1 & U & 1 & 1 & 1 & 5 \\
\hline
\end{tabular}

External validity: $\mathrm{A} 1=$ representative of the target population; $\mathrm{A} 2=$ appropriate recruitment of the participants; $\mathrm{A} 3=$ appropriate sampling frame; $\mathrm{A} 4=$ minimal non-response bias. Internal validity: $\mathrm{B} 1$ = data collected directly from the subjects (as opposed to a proxy); $\mathrm{B} 2=$ acceptable case definition; $\mathrm{B} 3=$ valid and reliable study instrument; $\mathrm{B} 4=$ same mode of data collection used for all subjects; $B 5=$ appropriate shortest prevalence period for the parameter of interest; B6 = appropriate numerator(s) and denominator(s) for the parameter of interest. 1: study met the criteria; 0: study did not meet the criteria; U: response was unclear. Quality score: $0-5$ high risk of bias; 6-8 moderate risk of bias; $>8$ low risk of bias. 


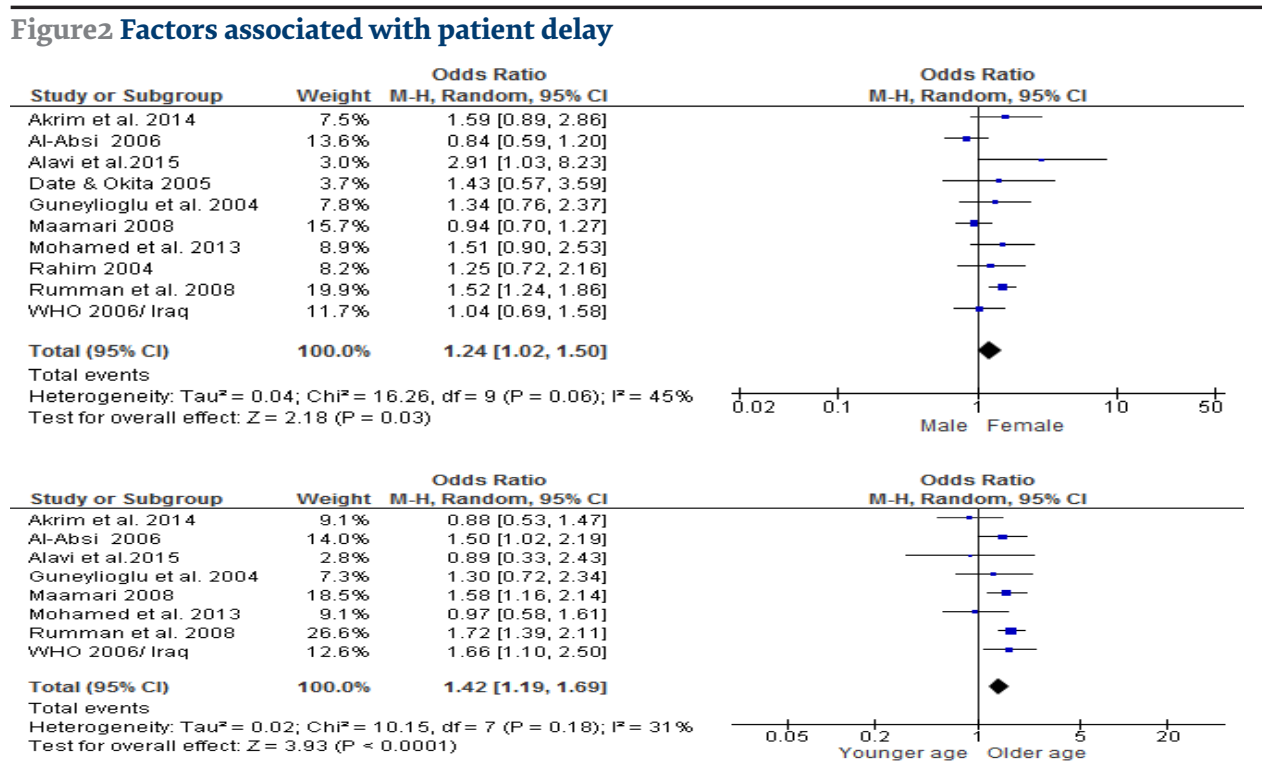

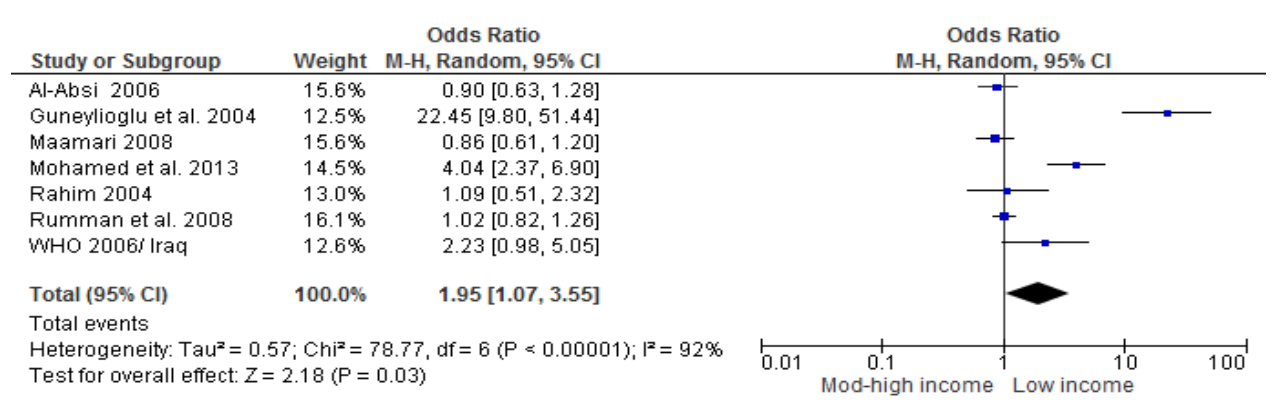

Odds Ratio

Study or Subgroup Weight M-H, Random, $95 \% \mathrm{Cl}$

$\begin{array}{lll}\text { Al-Absi } 2006 & 32.1 \% & 0.66[0.46,0.95] \\ \text { Maamari 2008 } & 39.5 \% & 0.95[0.71,1.27]\end{array}$

WHO 2006il Iraq $\quad 28.4 \%$

$0.63[0.42,0.93]$

Total $(95 \% \mathrm{Cl}) \quad 100.0 \%$

Total events

Heterogeneity: $\mathrm{Tau}^{2}=0.03 ; \mathrm{Chi}^{2}=3.80, \mathrm{df}=2(\mathrm{P}=0.15) ; \mathrm{I}^{2}=47 \%$

Test for overall effect: $Z=2.03(P=0.04)$
Odds Ratio

M-H, Random, $95 \% \mathrm{Cl}$

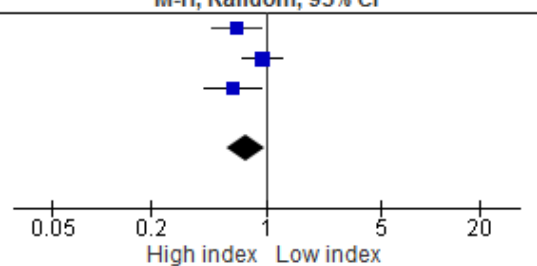

Risk Ratio

Study or Subgroup Weight M-H, Random, 95\% Cl

\begin{tabular}{lrr}
\hline Al-Absi 2006 & $16.6 \%$ & $0.84[0.67,1.04]$ \\
Guneylioglu et al. 2004 & $40.8 \%$ & $0.83[0.73,0.93]$ \\
Maamari 2008 & $23.1 \%$ & $0.66[0.56,0.79]$ \\
Rahim 2004 & $1.4 \%$ & $0.76[0.34,1.71]$ \\
WHO 2006i Iraq & $18.2 \%$ & $0.73[0.59,0.89]$ \\
& & \\
Total (95\% Cl) & $100.0 \%$ & $0.77[0.70,0.85]$
\end{tabular}

Total events

Heterogeneity: $\mathrm{Tau}^{2}=0.00 ; \mathrm{Chi}^{2}=4.84, \mathrm{df}=4(\mathrm{P}=0.30) ; \mathrm{I}^{2}=17 \%$

Test for overall effect: $Z=5.40$ ( $P<0.00001)$

Risk Ratio

M-H, Random, $95 \% \mathrm{Cl}$

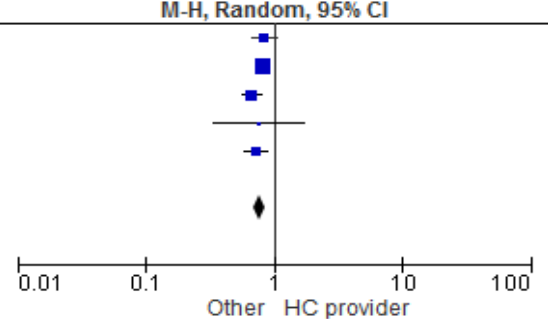

Odds Ratio

Odds Ratio

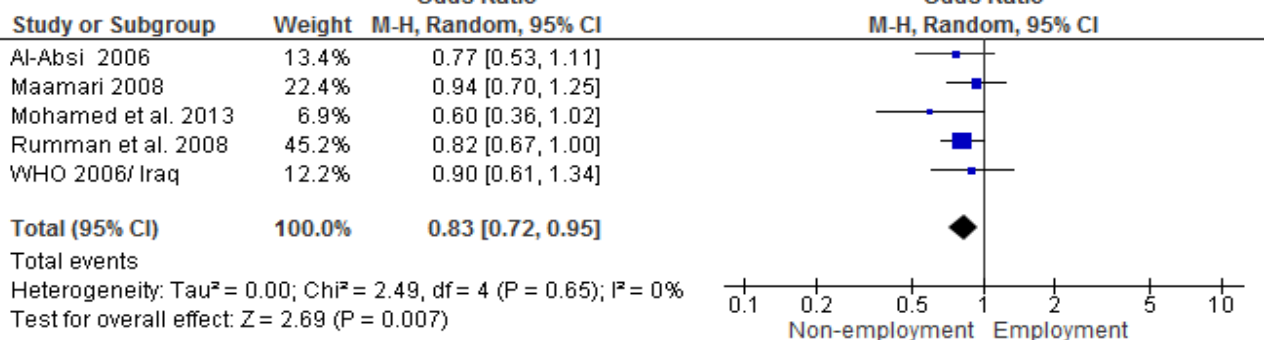




\section{Figure 3 Gender and facility at 1st consultation vs. health system delay}

\begin{tabular}{|c|c|c|c|c|c|c|}
\hline Study or Subgroup & Weight & $\begin{array}{l}\text { Odds Ratio } \\
\text { M-H, Random, } 95 \% \mathrm{Cl}\end{array}$ & \multicolumn{4}{|c|}{$\begin{array}{l}\text { Odds Ratio } \\
\text { M-H, Random, } 95 \% \mathrm{Cl}\end{array}$} \\
\hline Akrim et al. 2014 & $37.2 \%$ & $2.04[1.13,3.68]$ & & & & \\
\hline Guneylioglu et al. 2004 & $22.2 \%$ & $4.32[1.71,10.89]$ & & & & \\
\hline Rahim 2004 & $40.6 \%$ & $1.48[0.87,2.52]$ & & & & \\
\hline Total $(95 \% \mathrm{Cl})$ & $100.0 \%$ & $2.12[1.24,3.60]$ & & & & \\
\hline \multicolumn{7}{|c|}{ Total events } \\
\hline \multicolumn{3}{|c|}{$\begin{array}{l}\text { Heterogeneity: } \mathrm{Tau}^{2}=0.11 ; \mathrm{Chi}^{2}=3.92, \mathrm{df}=2(\mathrm{P}=0.14) ; \mathrm{I}^{2}=49 \% \\
\text { Test for overall effect: } \mathrm{Z}=2.77(\mathrm{P}=0.006)\end{array}$} & 0.01 & 0.1 & Female & 100 \\
\hline
\end{tabular}

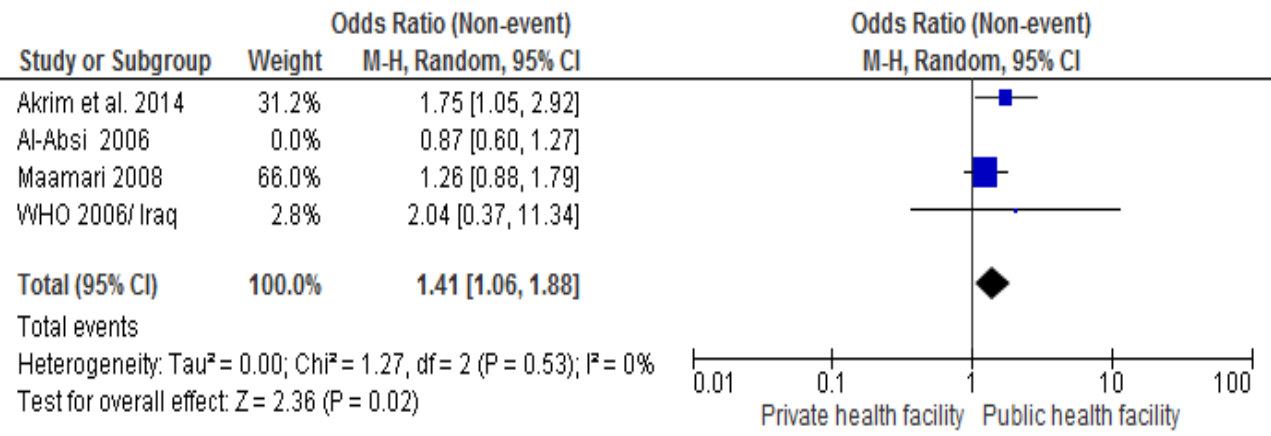

Removal of this study from the meta-analysis for subgroup analysis rendered the heterogeneity nonsignificant $\left(\mathrm{H}, \mathrm{P}=0.47 ; \mathrm{I}^{2}=0 \%\right)$. Two studies were different from the rest in terms of patient income (19,22); removal of these studies from the meta-analysis rendered the heterogeneity nonsignificant $\left(\mathrm{H}, \mathrm{P}=0.30 ; I^{2}=18 \%\right)$. Removal of the study having a higher cut-off point for the crowding index eliminated heterogeneity $\left(\mathrm{H}, \mathrm{P}=0.84 ; \mathrm{I}^{2}=0 \%\right)$ when considering this outcome (21).

\section{Health system factors}

Heterogeneity was significant $\left(P=0.14 ; I^{2}=49 \%\right)$ in terms of sex and was based on a single study (19). Removal of this study from the meta-analysis rendered the heterogeneity nonsignificant $\left(\mathrm{H}, \mathrm{P}=1.00 ; \mathrm{I}^{2}=0 \%\right)$.

\section{Grade quality of evidence}

The GRADE system produced a low quality grading for evidence in this review. This was a result of the shortcomings inherent in the observational study design of articles included in the review, plausibility of bias and small size estimates, which all have implications for the generalizability of estimates; for example, measurement of outcomes in these studies was dependent on patient self-reporting which created a possibility of recall bias. Nevertheless, the effects of exposure in these 12 studies were assessed as being similar and consistent thus, making them amenable to a meta-analysis.

\section{Discussion}

\section{Overview}

This review, which evaluated facilitators and barriers to TB diagnosis and health system delay, provides evidence for $\mathrm{TB}$ awareness and interventions targeting the elderly and those from lower-income settings, as a strategy for successful TB control in the MENA region. The predisposing factors that were significantly associated with patient delay were older age, being female, unemployment, low patient income, and crowding. Notably, being female was the only factor associated with both patient and health system delay.

\section{Implications for practice}

Tuberculosis control programme managers in the MENA region need to be cognizant of the range of factors which impact on patient and health systems delays. Such factors need to be considered when proposing policy interventions to reduce and contain transmission of TB disease, thus enhancing TB service delivery aimed at increased case detection rates in the MENA region.

This review provides evidence for the need to focus on health system enabling factors and to act on opportunities that will lead to a reduction in delays. Efforts to increase public awareness and to promote health education about $\mathrm{TB}$, especially in outreach areas, should be prioritized. Maintaining a high suspicion index for TB among all health care providers is mandatory. This can be achieved through effective training, including monitoring and evaluation, of health care professionals.

\section{Implications for research}

This systematic review underlined a couple of research-related caveats. The majority of studies had a cross-sectional study design which, while useful when measuring prevalence and identifying associations, nevertheless lack sthe ability to determine causality as do cohort studies (7). Recently, the MENA region has seen the fastest growing HIV epidemic. HIV-related data from 
the region is lacking. Research related to diagnostic, patient and health system delays associated with TB among HIV patient is required to assist national TB programme managers in constructing policies and planning interventions.

The health system in general, and TB control in particular, in the region is expected to be severely impacted by the actual political instability and complex emergencies in the region, which will provide an environment where TB is very likely to occur. Hence, it is vital to establish structures to contain any potential flare-up of cases in these circumstances. These structures might be achieved through factors identified by this work, and research assessing the post-crises situation and illustrating the gaps and needs for TB control.

In summary, this review provides evidence for facilitators on barriers to $\mathrm{TB}$ diagnosis and health system delays in the MENA region. For successful TB control in this region, TB awareness and interventions targeting the elderly and those in lower-income brackets, especially taking male-female differences into account, are essential.

\section{Limitations}

Most studies recruited patients from public health facilities and TB management units near the capital of the country. No recruitment from private health facilities or from the peripheries was done. The generalizability of this systematic review is limited as patients recruited from private health facilities and marginalized or remote areas were not included in the analysis.

Funding: None.

Competing interests: None declared.

\section{Facteurs associés aux retards en matière de diagnostic et de traitement de la tuberculose dans la Région du Moyen-Orient et de l'Afrique du Nord : analyse systématique}

\section{Résumé}

Contexte : L'instabilité politique, les sanctions économiques et la qualité inférieure des soins de santé ont une incidence négative sur la lutte contre la tuberculose dans la Région du Moyen-Orient et de l'Afrique du Nord.

Objectifs : La présente étude avait pour objectif de mettre en évidence les facteurs qui contribuent aux retards dans le diagnostic et le traitement de la tuberculose dans les pays de cette Région.

Méthodes: Deux examinateurs ont passé en revue indépendamment les articles éligibles aux critères de l'étude qu'ils ont identifiés au moyen de recherches exhaustives. Ensuite, ils ont extrait des données qui ont été soumises à une méta-analyse.

Résultats : Les retards dans le diagnostic de la tuberculose étaient associés à un âge plus élevé et à un revenu faible (odds ratio $[\mathrm{OR}]=1,49$; intervalle de confiance $[\mathrm{IC}]$ à $95 \%: 1,31-1,70)$ et $(\mathrm{OR}=1,26$; IC à $95 \%: 1,09-1,45)$ respectivement $(\mathrm{n}=17$ études). L'appartenance au sexe féminin était associée à un retard dans la prise en charge tant au niveau des patients que des systèmes de santé $[(\mathrm{OR}=1,24 ; \mathrm{IC}$ à $95 \%: 1,02-1,50)$ et $(\mathrm{OR}=1,68 ; \mathrm{IC}$ à $95 \%: 1,18-2,38)$ respectivement. La connaissance et la perception de la tuberculose, le fait d'avoir un emploi et un faible niveau de promiscuité jouaient un rôle déterminant pour limiter les retards dans la prise en charge des patients. Le système GRADE (grade donné aux recommandations, examen, élaboration et évaluation) a évalué les données comme étant de faible qualité.

Conclusion : La présente analyse fournit aux facilitateurs des bases factuelles sur les obstacles en matière de diagnostic de la tuberculose ainsi que sur les retards liés aux systèmes de santé. Pour réussir à lutter contre la tuberculose dans la Région du Moyen-Orient et de l'Afrique du Nord, la sensibilisation à la maladie et les interventions ciblant les personnes âgées et celles issues des milieux à revenu faible sont essentielles, en accordant une attention particulière aux différences entre les sexes.

$$
\text { الخاليا الطيب، إليز بيترسون، مارك إلمجيطة بالتأخر في تشخيص السل وعلاجه في الشرق الأوسط وشهال أفريقيا: استعر اض منهجي الله }
$$

الخلفية: يؤثر انعدام الاستقرار السياسي، والعقوبات الاقتصادية، وتدني نوعية الرعاية الصحية سلبا على جهود مكافحة السل في منطقة الشرق الأوسط وشمال أفريقيا.

$$
\text { الأهداف: استهدفنا توضيح العو امل المسهمة في تأخير تشخيص السل وعلاجه في بُّلدان منطقة الشرق الأوسط وشمال أفريقيا. }
$$

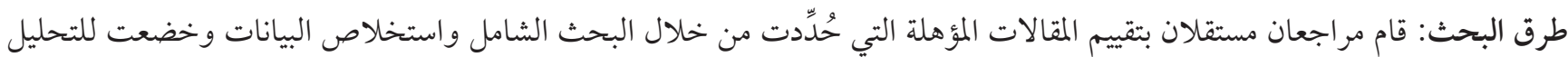


النتائج: اقترن تأخير تشخيص السل بتقدم العمر وانخفاض الدخل (OR = 1.49; 95\% CI: 1.31-1.70) و (OR = 1.26; 95\% CI: 1.09-1.45)

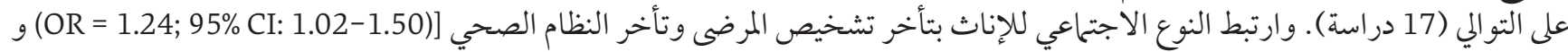

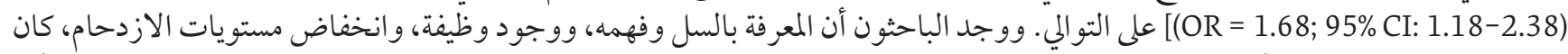

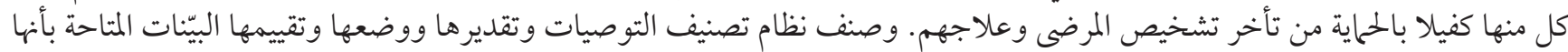
منخفضة الجودة.

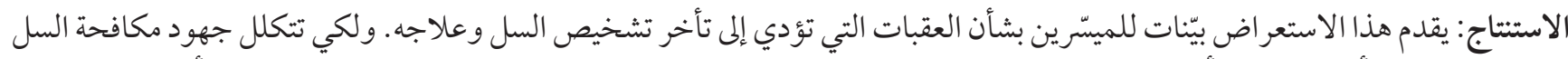

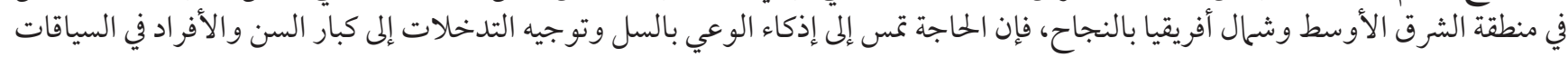

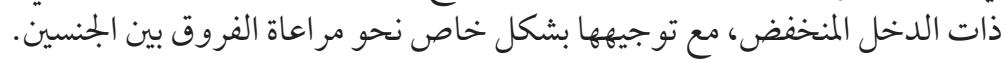

\section{References}

1. Global tuberculosis report 2016. Geneva: World Health Organization; 2016 (http://apps.who.int/iris/bitstream/10665/250441/1/978 9241565394-eng.pdf, accessed 28 September 2019).

2. Asch S, Leake B, Anderson R, Gelberg L. Why do symptomatic patients delay obtaining care for tuberculosis? Am J Respir Crit Care Med. 1998;157(4 I):1244-8.

3. Global tuberculosis report 2014. Geneva: World Health Organization; 2014 (http://apps.who.int/iris/bitstre am/10665/137094/1/9789241564809_eng.pdf, accessed 28 September 2019).

4. Rao VK, Iademarco EP, Fraser VJ, Kollef MH. Delays in the suspicion and treatment of tuberculosis among hospitalized patients. Ann Intern Med. 1999;130(5):404-11.

5. Lönnroth K, Corbett E, Golub J, Godfrey-Faussett P, Uplekar M, Weil D, et al. Systematic screening for active tuberculosis: Rationale, definitions and key considerations. Int J Tuberculosis Lung Dis. 2013 Mar;17(3):289-98. doi:10.5588/ijtld.12.0797

6. Cock D. Editorial. Tuberculosis control : did the programme fail or did we fail the programme? Trop Med Int Heal. 1997;2(8):715-8 (http://onlinelibrary.wiley.com/doi/10.1046/j.1365-3156.1997.do1-388.x/epdf, accessed 28 September 2019).

7. Finnie RKC, Khoza LB, van den Borne B, Mabunda T, Abotchie P, Mullen PD. Factors associated with patient and health care system delay in diagnosis and treatment for TB in sub-Saharan African countries with high burdens of TB and HIV. Trop Med Int Heal. 2011 Apr 14;16(4):394-411. doi:10.1111/j.1365-3156.2010.02718.x

8. Definition: MENA. Washington DC: World Bank; 2014 (https://www.worldbank.org/en/region/mena, accessed 25 January 2020

9. Pierre-Louis AM, Ayodeji F, Karam HS. Public health in the Middle East and North Africa : meeting the challenges of the twenty-first century. Washington DC: World Bank; 2004 (https://openknowledge.worldbank.org/handle/10986/15012 License: CC BY 3.0 IGO, accessed 28 September 2019).

10. Thomas C. A literature review of the problems of delayed presentation for treatment and non-completion of treatment for tuberculosis in less developed countries and ways of addressing these problems using particular implementation of the DOTS strategy. J Manag Med. 2002;16(4-5):371-400. PMID:124636

11. Moher D, Liberati A, Tetzlaff J, Altman DG. Preferred reporting items for systematic reviews and meta-analyses: the PRISMA statement. BMJ. 2009 Jul 21;339:b2535. doi:10.1136/bmj.b2535.

12. Jahangir E, Irazola V, Rubinstein A. Need, enabling, predisposing, and behavioral determinants of access to preventative care in Argentina: analysis of the national survey of risk factors. PLoS One. 2012;7(9):e45053. doi:10.1371/journal.pone.0045053

13. Wells G, Shea B, O'Connell D, Robertson J, Peterson J, Welch V, et al. The Newcastle-Ottawa Scale (NOS) for assessing the quality if nonrandomized studies in meta-analyses. Evid based public Heal. 2012 (http://www.evidencebasedpublichealth.de/download/ Newcastle_Ottowa_Scale_Pope_Bruce.pdf, accessed 28 September 2019).

14. Hoy D, Brooks P, Woolf A, Blyth F, March L, Bain C, et al. Assessing risk of bias in prevalence studies: modification of an existing tool and evidence of interrater agreement. Elsevier Inc J Clin Epidemiol. 2012;65:934-9. doi:10.1016/j.jclinepi.2011.11.014

15. Werfalli M, Musekiwa A, Engel ME, Ross I, Kengne AP, Levitt NS. The prevalence of type 2 diabetes mellitus among older people in Africa: a systematic review study protocol. BMJ Open. 2014 Jun 17;4(6):e004747. doi:10.1136/bmjopen-2013-004747

16. Rumman KA, Sabra NA, Bakri F, Seita A, Bassili A. Prevalence of tuberculosis suspects and their healthcare-seeking behavior in urban and rural Jordan. Am J Trop Med Hyg. 2008;79(4):545-51. PMID:18840742

17. Ekinci GH, Karakaya E, Ongel EA, Haciomeroglu O, Yilmaz A. Patient and Doctor Delays in smear-negative and smear-positive pulmonary tuberculosis patients attending a referral hospital in Istanbul, Turkey. ScientificWorldJournal. 2014;2014:158186. doi:10.1155/2014/158186

18. Alavi SM, Bakhtiyariniya P, Albagi A. Factors associated with delay in diagnosis and treatment of pulmonary tuberculosis. Jundishapur J Microbiol. 2015;8(3):8-11. (http://www.jjmicrobiol.com/?page=article\&article_id=19238, accessed 28 September 2019).

19. Güneylioglu D, Yilmaz A, Bilgin S, Bayram U, Akkaya E. Factors affecting delays in diagnosis and treatment of pulmonary tuberculosis in a tertiary care hospital in Istanbul, Turkey. Med Sci Monit. 2004;10(2):CR62-7. PMID:147370 
20. Al Absi AN. Case finding in tuberculosis patients: diagnostic and treatment delays and their determinants. Yemeni Heal Med Res J. 2006;3(11):30-64.

21. Maamari F. Case-finding tuberculosis patients: diagnostic and treatment delays and their determinants. East Mediterr Health J. 2008;14(3):531-45. PMID:18720617

22. Mohamed EY, Abdalla SM, Khamis AA, Abdelbadea A, Abdelgadir MA. Factors associated with patient delay in accessin pulmonary tuberculosis care, Gezira State, Sudan, 2009. East Mediterr Health J. 2013;19:114-8. PMID:23516819

23. Rahim MSAA. Delay in the diagnosis and treatment of new smear- positive pulmonary tuberculosis in Khartoum State, Sudan [thesis]. Olso: University of Oslo; 2004 (http://urn.nb.no/URN:NBN:no-10327, accessed 28 September 2019).

24. Akrim et al. Determinants of consultation, diagnosis and treatment delays among new smear-positive pulmonary tuberculosis patients in Morocco: a cross-sectional study. East Mediterr Heal J. 2014 Dec;20(11):707. doi:10.26719/2014.20.11.707

25. Diagnostic and treatment delay in tuberculosis in 7 countries of the Eastern Mediterranean Region,; 25a,25b,25c,25d donated to studies conducted in Iraq, Iran, Egypt and Somalia respectively. Cairo: World Health Organization Regional Office.for the Eastern Mediterranean; 2008 (WHO-EM/TDR/009/E/10.06/1000) (http://applications.emro.who.int/dsaf/dsa710.pdf, accessed 28 September 2019).

26. Masjedi MR, Cheragvandi A, Hadian M, Velayati AA. Reasons for delay in the management of patients with pulmonary tuberculosis. East Mediterr Heal J. 2002;8(2-3):324-9. PMID:15339120

27. Mirsaeidi SM, Tabarsi P, Mohajer K, Falah-Tafti S, Jammati HR, Farnia P, et al. A long delay from the first symptom to definite diagnosis of pulmonary tuberculosis. Arch Iran Med. 2007;10(2):190-3.

28. Shamaei M, Marjani M, Baghaei P, Chitsaz E, Rezaei Tabar E, Abrishami Z, et al. Drug abuse profile - patient delay, diagnosis delay and drug resistance pattern - among addict patients with tuberculosis. Int J STD AIDS. 2009;20(5):320-3. doi:10.1258/ ijsa.2008.008299

29. Okur E, Yilmaz A, Saygi A, Selvi A, Süngün F, Öztürk E, et al. Patterns of delays in diagnosis amongst patients with smear-positive pulmonary tuberculosis at a teaching hospital in Turkey. Clin Microbiol Infect. 2006 Jan;12(1):90-2. https://doi.org/10.1111/ j.1469-0691.2005.01302.x

30. Okutan O, Kartaloglu Z, Cerrahoglu K, Ilvan A, Tozkoparan E, Aydilek R. Delay in the diagnosis of Turkish servicemen with pulmonary tuberculosis. Mil Med. 2005;170(3):211-3.

31. Bashour H, Mamaree F. Gender differences and tuberculosis in the Syrian Arab Republic: patients' attitudes, compliance and outcomes. East Mediterr Health J. 2003 Jul;9(4):757-68. PMID:15748072

32. Nasehi M, Hassanzadeh J, Rezaianzadeh A, Zeigami B, Tabatabaee H, Ghaderi E. Diagnosis delay in smear positive tuberculosis patients. J Res Med Sci. 2012;17(11):1001-4. PMID:23833571

33. Shahriyar M, Niazi A, Karimian R, Naroii E, Pishjoo M, Nikoseresht M, et al. Causes of delay in diagnosis of smear-positive pulmonary tuberculosis patients referred to the tuberculosis center of Zahedan. Zahedan J Res Med Sci. 2012;14(8):29-32.

34. Yilmaz A, Boa S, Sulu E, Durucu M, Yilmaz D, Baran A, et al. Delays in the diagnosis and treatment of hospitalized patients with smear-positive pulmonary tuberculosis. Respir Med. 2001;95(10):802-5. doi:10.1053/rmed.2001.1156

35. Date J, Okita K. Gender and literacy: factors related to diagnostic delay and unsuccessful treatment of tuberculosis in the mountainous area of Yemen. Int J Tuberc Lung Dis. 2005;9(6):680-5. PMID:15971397 